\title{
A New Sensitive, Thiol Tolerant Method for the Determination of Inorganic Pyrophosphatase
}

\author{
REIJO LAHTI, IRMELI JANTUNEN and JUKKA HEINONEN
}

Department of Biochemistry, University of Turku, SF-20500 Turku 50, Finland

In this work a new sensitive, thiol tolerant method for the determination of inorganic pyrophosphatase (EC 3.6.1.1) was developed. It is based on the formation of phosphomolybdatetriethylamine complex, which in acid-acetone mixture forms a white, homogenous precipitate, the turbidity of which can be accurately measured spectrophotometrically at $355 \mathrm{~nm}$. This method can be easily applied to all the $P_{i}$-producing enzymes whose substrates are stable enough in our acidic experimental conditions.

We have recently shown that inorganic pyrophosphatase (EC 3.6.1.1, hereafter referred to as PPase) of Streptococcus faecalis is regulated at the activity level via the ratio of reduced glutathione to oxidized glutathione. ${ }^{1,2}$ The enzyme exists in two interconvertible forms which differ in activity. The highly active form of enzyme is labile, and is stabilized by thiol compounds in vitro. ${ }^{3}$ Our purpose is to study the kinetics of these two enzyme forms. We have recently introduced a new method for the determination of inorganic orthophosphate which is suitable for most purposes. ${ }^{4}$ However, the sensitivity of that method is somewhat too low when the kinetics of inorganic pyrophosphatase is studied at low pyrophosphate concentrations. Furthermore, the various modifications of the Fiske-SubbaRow method generally used for studies on PPase kinetics ${ }^{5-7}$ are highly sensitive for thiol compounds. The kinetics of the highly active form of $S$. faecalis PPase has to be measured in the presence of thiol compounds, and so a method insensitive to thiols had to be developed.

\section{MATERIALS AND METHODS}

Chemicals. Commercially available chemicals of analytical grade were used without any purification. ATAM solution (acetone-triethylamine-acid-molybdate) was prepared daily by mixing 4 vol of $10 \mathrm{mM}\left(\mathrm{NH}_{4}\right)_{6} \mathrm{Mo}_{7} \mathrm{O}_{24} \cdot 4 \mathrm{H}_{2} \mathrm{O}$ with 2 vol of $2.5 \mathrm{~N} \mathrm{H}_{2} \mathrm{SO}_{4}, 1$ vol of acetone and 0.075 vol of triethylamine.

Assay of inorganic pyrophosphatase. The reaction mixture was as follows: $150 \mu \mathrm{l}$ of the appropriate dilution (about 1.9-0.2 mUnits; $U=\mu \mathrm{mol}$ product formed $/ \mathrm{min}$, dilution with 0.05 $\mathrm{M}$ Tris/HCl $\mathrm{pH}$ 8.0) of the homogenous enzyme preparation purified according to Lahti and Niemi, ${ }^{8} 25 \mu \mathrm{l}$ of $9 \mathrm{mM} \mathrm{MgCl} 2,25 \mu \mathrm{l}$ of $9 \mathrm{mM}$ $\mathrm{Na}_{4} \mathrm{PP}_{\mathrm{i}}$ and $25 \mu \mathrm{l}$ of $0.05 \mathrm{M}$ Tris/ $\mathrm{HCl} \mathrm{pH}$ 8.0. The reaction took place at $25^{\circ} \mathrm{C}$, and it was started by the addition of $\mathrm{PP}_{\mathrm{i}}$. After the appropriate incubation time the reaction was stopped by adding 25 $\mu \mathrm{l}$ of $1.2 \mathrm{M}$ trichloroacetic acid. ATAM solution $(0.9 \mathrm{ml})$ was pipetted to the reaction mixture. After vigorous mixing with a vortex mixer $0.1 \mathrm{ml}$ of $1 \mathrm{M}$ citric acid was added to the tube, and the white, homogenous turbidity of the phosphomolybdate-triethylamine complex was measured spectrophotometrically at $355 \mathrm{~nm}$. A reaction mixture, where trichloroacetic acid was added before $\mathbf{P P}_{\mathrm{i}}$, was used as a blank. Furthermore, for the determination of $P_{i}$ standard for PPase assay $25 \mu \mathrm{l}$ of Tris/ $\mathrm{HCl} \mathrm{pH} 8.0$ was substituted by $25 \mu \mathrm{l}$ of appropriate $\mathrm{P}_{\mathrm{i}}$ solutions $\left(9-180 \mathrm{nmol} \mathrm{P}_{\mathrm{i}}\right.$, dissolved in $0.05 \mathrm{M}$ Tris/ $\mathrm{HCl} \mathrm{pH} 8.0$ ), and trichloroacetic acid was again added before $\mathrm{PP}_{\mathrm{i}}$ to prevent the enzymatic reaction. 


\section{RESULTS}

Based on the observation that inorganic pyrophosphate and orthophosphate can be separated by selective precipitation of $P_{i}$ as a phosphomolybdate-triethylamine complex ${ }^{9}$ we decided to search for conditions where the turbidity of the precipitate could be accurately determined. The precipitate formed as described by Cartier and Thuillier ${ }^{9}$ is flocculent, and cannot be measured as such. In addition, if triethylamine is added to the acetone-acid-molybdate (AAM) mixture described by us ${ }^{4}$ no precipitation occurs. However, when the ratio of the concentrations of the components in the AAM is changed to that of ATAM presented in Materials and Methods the phosphomolybdate-triethylamine precipitate becomes homogenous enough to be measured spectrophotometrically.

The turbidity was developed in a couple of minutes as the contents of the test tube were thoroughly mixed after the addition of ATAM solution. After that the turbidity decreased by about $10 \%$ in 30 min but the relative decrease was independent of the initial amount of the turbidity. The blank value did not change significantly in $30 \mathrm{~min}$ (Fig. 1). To overcome the interference of slow decrease in turbidity the

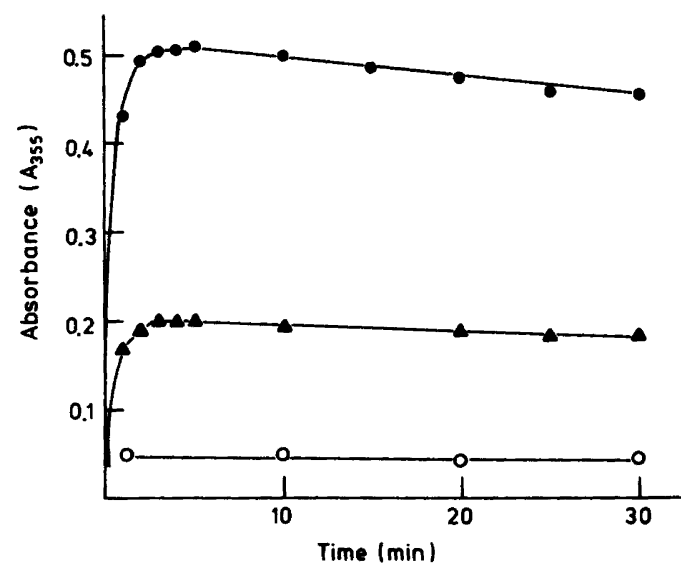

Fig. 1. Stability of the turbidity of the phosphomolybdate-triethylamine complex. Enzymatic hydrolysis of inorganic pyrophosphate catalyzed by inorganic pyrophosphatase was arrested after the reaction time of $0 \mathrm{~min}(\mathrm{O}), 5 \mathrm{~min}(\Delta)$, and 15 $\min (\mathbf{O})$, and the turbidity of the white precipitate was measured at intervals spectrophotometrically at $355 \mathrm{~nm}$. Distilled water was used as a blank. samples were measured at fixed times after the addition of ATAM solution.

High salt $(1 \mathrm{M} \mathrm{NaCl})$ and sucrose $(200 \mathrm{mg} / \mathrm{ml})$ concentrations exerted no measurable effects on the turbidity formed or on the blank value. Furthermore, a strong reductant, ascorbic acid, at $1 \mathrm{mM}$ concentration had no effect on the formation or stability of the precipitate. Thiol compounds, such as L-cysteine and 2-mercaptoethanol, increased the blank value when present in high concentrations. This interference could be easily overcome by making the standard in the presence of the thiol compounds. When the concentration of thiol compounds was less than $10 \mathrm{mM}$, no corrective measures were required.

The standard curve for the routine PPase assay is presented in Fig. 2. The lower limit of the assay is about $1 \mathrm{nmol} P_{i}$. In the routine PPase assay the amount of $P_{i}$ produced was a linear function of the amount of the enzyme up to about $20 \mathrm{nmol}$ of $P_{i}$ liberated (corresponding to about $A_{355}=0.7$ ). The precision of the PPase assay was determined by using aliquots of the same enzyme preparation in ten different reaction mixtures. The arithmetic mean of the measured activities was $3.5 \mathrm{nmol}$ of $P_{i}$ formed in $15 \mathrm{~min}\left(0.130 A_{355} / 15 \mathrm{~min}\right)$, and the range of the values was $0.32 \mathrm{nmol}(0.125-0.137$ $\left.A_{355}\right)$ or $9.2 \%$ of the mean value.

\section{DISCUSSION}

The aim of this work was to develop a method for the determination of inorganic pyrophosphatase that is sensitive enough for kinetic studies and is resistant to thiol compounds. The latter

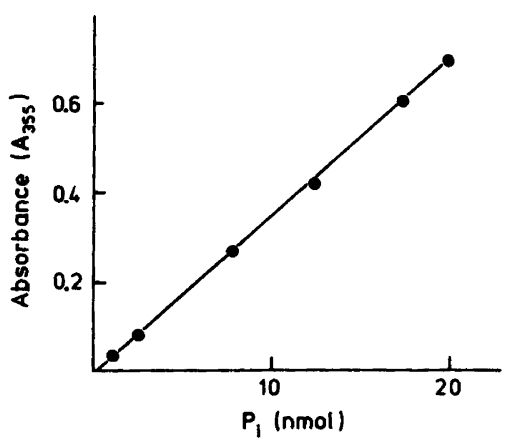

Fig. 2. Standard curve for the assay of inorganic pyrophosphatase. For further details see Materials and Methods. 
demand is especially important when the kinetics of the highly active form of $S$. faecalis inorganic pyrophosphatase is studied. ${ }^{3}$ The radiochemical method presented by Heinonen ${ }^{10}$ fulfills both of these demands excellently, but the price of the labelled substrate and the inconvenience of working with radioactive solutions encouraged us to look for an alternative. Our new method, which is a modified combination of the methods described by Cartier and Thuillier ${ }^{9}$ and Heinonen and Lahti, ${ }^{4}$ is tolerant to thiol compounds and it is about fifty times as sensitive as that described by us recently. ${ }^{4}$ This method is easily applicable to all the $P_{i}$ producing enzymes whose substrates are so stable that they do not hydrolyze significantly between the additions of trichloroacetic acid and citric acid (see Materials and Methods). When citric acid has been added the acid catalyzed release of $P_{i}$ causes no problems because all extra molybdate is complexed with citrate. This method requires no expensive materials and special instruments, and hence can be used in any laboratory.

While this manuscript was in preparation we learned a method described by Eibl and Lands ${ }^{11}$ where phosphomolybdate precipitate was formed by Triton $\mathrm{X}-100$. However, this method was not checked for possible interferences, and evidently it has not been much used.

\section{REFERENCES}

1. Lahti, R. and Heinonen, J. J. Gen. Microbiol. 125 (1981) 185.

2. Lahti, R. and Suonpää, M. J. Gen. Microbiol. 128 (1982) 1023.

3. Lahti, R. and Heinonen, J. Acta Chem. Scand. B 35 (1981) 33.

4. Heinonen, J. and Lahti, R. Anal. Biochem. 113 (1981) 313.

5. Josse, J. J. Biol. Chem. 241 (1966) 1948.

6. Schreier, E. and Höhne, W. E. FEBS Lett. 90 (1978) 93.

7. Moe, O. A., Pham, S., Dang, T. and Styer, L. Arch. Biochem. Biophys. 196 (1979) 73.

8. Lahti, R. and Niemi, T. J. Biochem. 90 (1981) 79.

9. Cartier, P. H. and Thuillier, L. Anal. Biochem. 44 (1971) 397.

10. Heinonen, J. Anal. Biochem. 37 (1970) 32.

11. Eibl, H. and Lands, W. E. M. Anal. Biochem. 30 (1969) 51.

Received October 18, 1982. 